\title{
Razão e imaginação para todos os tempos
}

Otávio Velho

RESUMO: Partindo das relações entre razão e imaginação enquanto modalidades de conhecimento na obra do filósofo Espinosa, são apresentadas diversas manifestações do imaginário. Definem-se as vulnerabilidades do imaginário, utilizando como exemplo as fake news. Após considerações sobre a razão tomando como caso exemplar o da Ciência, distingue-se um imaginário triste e um imaginário alegre. E privilegia-se este último para a constituição de um imaginário da ciência.

PALAVRAS-CHAVE:

Razão. Imaginação. Fake news. Presságios. Ciência.

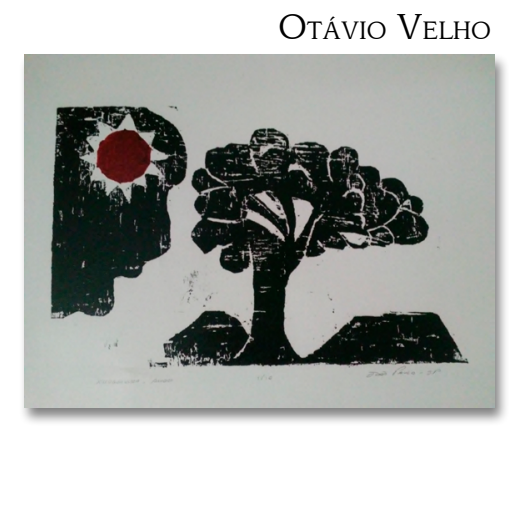

\section{Reason and imagination for all times}

\section{Otávio Velho}

Professor emérito da Universidade Federal do Rio de Janeiro (Museu Nacional), membro titular da Academia Brasileira de Ciências (ABC) e presidente de honra da Sociedade Brasileira para o Progresso da Ciência (SBPC).

E-mail: otaviogvelho@gmail.com

\begin{abstract}
The relations between reason and imagination as modes of knowledge in the work of the philosopher Spinoza are used as a starting point. Different expressions of the imaginary are presented as well as a definition of its vulnerabilities taking fake news as a case. After considerations about reasoning having Science as an example, a distinction is made between a sorrowful imaginary and a joyful one. And a special place is then reserved for a joyful imaginary in the constitution of an imaginary of science.
\end{abstract}

KEYWORDS: Reason. Imagination. Fake news. Omens. Science.

RECEBIDO: 30/08/2020

AprovADO: 30/09/2020 


\section{Imaginação e fake news ${ }^{1}$}

A melhor filosofia sugere que a razão é o caminho privilegiado para a libertação. Pois entre nós é possível argumentar que a questão está hoje posta publicamente, de modo exemplar e único, na maneira pela qual a ciência vem ultimamente se afirmando no combate contra a carência de informação, a desinformação e as notícias falsas - as chamadas fake news - e seu potencial de criação de realidades paralelas. Esse combate tem se refletido na atuação seja de especialistas, seja de organizações como a Sociedade Brasileira para o Progresso da Ciência (SBPC) e a Academia Brasileira de Ciências (ABC), seja da chamada comunidade científica em seu conjunto. Essa defesa da ciência vem se dando de tal modo - inédito entre nós - que se tornou referência central a pautar os debates nacionais, a partir das polêmicas concernentes aos cuidados preventivos e curativos no contexto da presente pandemia do novo coronavírus - sem falar da questão, cada vez mais premente, das mudanças climáticas e do papel da Amazônia, que no debate acabou sendo potencializada pela questão anterior, devido à origem comum das preocupações com as ações oriundas do governo federal.

Todas essas ações são, aparentemente, movidas por uma mesma lógica. Contudo, ressalvadas as especificidades locais, é importante ressaltarmos que o fenômeno das fake news é global. A Organização Mundial da Saúde, por exemplo, constituiu uma comissão que constatou impressionante disseminação de notícias, tais como a de que a tecnologia $5 \mathrm{G}$ seria responsável pela disseminação do vírus. Outro caso é a renitência do movimento antivacina, que possui longa pré-história entre nós, desde a "revolta da vacina" de 1904. Apesar de a rejeição à vacinação ser aparentemente menor no Brasil hoje que em outros países, a ideia de que as vacinas em geral são aplicadas pelo governo com a intenção de matar a população, sobretudo de idosos, é corrente.

1 Agradeço a Amir Geiger, Diogo Pires Aurélio, Ennio Candotti, Juarez Humberto Ferreira, Luiz Davidovich, Luiz Eduardo Soares, Rodrigo Toniol, Pedro Paulo Pereira, Sidarta Ribeiro e Stela Abreu pelos generosos comentários, inspiração e apoio de várias ordens na preparação deste texto. 
Nos debates nacionais a que nos referimos, a defesa da razão e da ciência tem identificado como adversários principais, por um lado, a própria política governamental e, por outro, a disseminação em massa de notícias falsas por meio da internet. No caso dessas últimas, o combate a elas tem se concentrado na disseminação que se dá de forma politicamente interessada e planejada, a chamada "guerra cibernética", que aparentemente altera de modo profundo o jogo político. Tendo se tornado uma preocupação que vai muito além de nossas fronteiras, essa questão retoma - no entanto, tardia e nem sempre reconhecidamente - preocupações antigas que, em contexto e meio diversos, desde as décadas de 1920 e 1930, polarizaram as atenções; sobretudo por conta da ameaça fascista de então (VELHO, 2019b). Manipulação talvez seja a palavra que sintetize essas preocupações.

Reconhecida a importância desses debates e levando-os em conta, nossa intenção no presente texto é explorar, em caráter preliminar e introdutório, outra vertente possível que até agora não tem merecido a mesma atenção. Ela parte da constatação de que há certos fenômenos que possuem traços aproximáveis aos já mencionados, mas onde o caráter manipulativo não parece ocupar o mesmo lugar sugerido nos atuais debates. Na literatura antropológica africanista, por exemplo, ocorre lembrarmos o venerável tema das "acusações de bruxaria" (EVANS-PRITCHARD, 1937), a que poderíamos juntar o dos "tabus alimentares". Próximo a nós, dentre muitas outras, há a figura da Besta-Fera e as especulações populares a respeito de seu possível retorno e suas implicações apocalípticas (VELHO, 2007). A isso poderíamos acrescentar o chupa-cabra, por exemplo. Se fenômenos como esse têm a ver com uma desconfiança em relação às instituições, o mínimo que podemos dizer é que qualitativamente não se trata de falta recente de confiabilidade.

Entrementes, dada a carência, no atual momento, de pesquisas que sustentem empiricamente uma discussão desse tipo, tendo como referência o objeto dos debates em curso, e posto que partimos do pressuposto de que os próprios termos de debate estão a merecer uma reflexão, a estratégia aqui - repetindo: preliminar e introdutória - tomará como ponto de partida uma 
apresentação do tema da imaginação tal como desenvolvida pelo filósofo Baruch de Espinosa (1632 - 1677). Esse tema vai muito além dos exemplos que apresentamos acima, escolhidos somente por sua afinidade imediata com o que podemos colher a propósito dos debates atuais. Para tal, dada a complexidade do assunto no próprio Espinosa, simplesmente daremos a palavra inicialmente ao especialista que, a nosso ver, melhor desenvolveu em plano internacional o assunto até agora, o que possivelmente poderá nos ajudar em um esforço de aggiornamento do próprio argumento antropológico.

\section{Imaginação e afeto}

A estreita relação entre razão e libertação, a que nos referimos no início, no caso de Espinosa, parece ter obscurecido outros aspectos de sua obra necessários para que procuremos uma compreensão mais completa do seu sentido geral. Esses aspectos sintomaticamente o levaram em determinado momento à louvação, em uma linha maquiaveliana, à perspicácia dos políticos em comparação com os "filósofos", a que já fizemos referência em momento anterior (VELHO, 2019a). Diogo Pires Aurélio, em diversos trabalhos, tem chamado a atenção particularmente para o tópico da imaginação. Aqui nos concentraremos em um desses trabalhos, o mais alentado e sistemático a respeito deste assunto (cf. AURÉLIO, 2000), que utilizaremos como fio condutor.

De fato, sempre acompanhando perspicazmente Espinosa, ele afirma que o que "acontece com todos os homens a maior parte do tempo" (AURÉLIO, 2000, p. 160) é buscar conservar-se na existência e na perseverança no ser. O critério para isso é o da utilidade na preservação da existência apreendida a partir da experiência, e não a verdade. Isso leva a que o "[...] conhecimento de que a imaginação está privada" seja o da "natureza da aparência", a aparência sendo, no entanto, não um simulacro, mas "[...] a natureza necessária da representação do encontro de corpos exteriores com um corpo que é afectado" (AURÉLIO, 2000, p. 220). São representações de acordo com a contingência, e não com a causalidade. Assim: 
O que Espinosa declara é a impossibilidade de sair da caverna, ou seja, a inutilidade de especular sobre uma cidade que é um mito, como se os homens pudessem deixar de ser aquilo que são, actuar à margem da cadeia em que, mental e fisicamente, estão inseridos, furtar-se, em suma, ao jogo da imaginação e dos afectos que é o meio em que se trava a luta pelo poder. (AURÉLIO, 2000, p. 26).

No terreno da filosofia política, isto constitui uma revolução ontológica, a "[...] da política pensada, baconianamente, como domínio sobre a natureza, à política pensada como cultura e desenvolvimento da natureza" (AURÉLIO, 2000, p. 183). Essa revolução se associa à sua (de Espinosa) proposta de um imanentismo radical que parece encontrar eco hoje, mais de três séculos depois, inclusive na postura consequentemente distante de qualquer antropomorfismo. Esse imanentismo foi expresso de forma incontornável por outro filósofo, Friedrich Nietzsche (1844 - 1900) - que se declarava espinosano (VELHO, 2020) - ao bradar: "Deus está morto!". O brado é entendido como um alerta contra todo e qualquer transcendentalismo, aí incluídas as suas sombras. Todas elas, sob risco de:

[...] emergir o fantasma de uma causa que seria primeira e última, de um deus ficcionado para além da natureza, que o mesmo é dizer, de um deus imaginado, não a agir necessariamente coagido apenas pelas leis da sua natureza, mas a operar, a produzir efeitos que alegadamente o transcendiam. (AURÉLIO, 2000, p. 182).

Ao inverso, trata-se de insistirmos na imanência das causas aos sucessivos efeitos e de caracterizar a transcendência como uma imanência que não se reconhece enquanto tal. É como se estivéssemos diante de uma epistème poderosa, de que não é possível nos livrarmos facilmente. Isto porque ela não se resolve na questão do teísmo e do ateísmo e espoca mesmo do lado que se representa como sendo o da razão. Por exemplo, na forma de valores que contaminam o entendimento, como pode ser o caso de uma associação entre moralidade e política tal como herdada do cristianismo, que nos impede de captar a lógica própria desta 
última, refugiando-se na normatividade (VELHO, 2019a). Quantas de nossas análises e de nossos conceitos podem ser considerados isentos dessa contaminação, própria ao não-lugar das utopias? O que é para nós uma "sociedade"? Ou uma "cultura"? Novos transcendentais exteriores à natureza e revestidos de causalidade? Assim, voltamos à questão da imaginação, a que acontece com todos os homens a maior parte do tempo. Pois por isso - e só por isso - as ideias da imaginação são consideradas "inadequadas", já que seu critério é o da utilidade (mesmo que possa haver erro de cálculo) e não a verdade. Inadequadas da perspectiva do eterno (sub specie aeternitatis), o que não lhes retira a eficácia afetiva. Utilidade e afeto combinados. Talvez assim é que, emprestando à imaginação uma dignidade filosófica, Martin Heidegger, confrontado com as primeiras imagens da Terra tiradas do espaço, teria declarado que essa não seria mais a terra em que vive o homem, pois o solo que ele habita (Dasein) não poderia ser redondo (VELHO, 2019b). Não podemos deixar de associar isso, no entanto, à retomada atual da polêmica sobre a terra plana, emprestando-lhe, porém, outra dimensão existencial, além de uma nova atualidade metafórica (the world is flat) com a redefinição e compressão prática do espaço e do território levadas a cabo na era da conectividade global.

\section{Profecias}

Poderíamos falar, então, em uma representação imaginativa das coisas:

Os signos não se referem directamente aos objectos: referem-se à sobreposição confusa de um objecto a outro objecto. Nesse sentido, eles constituem sinais, indícios das operações produzidas pela contínua actividade dos seres. São esses sinais que, ao nível da imaginação, se tomam por representações das coisas, dando origem às cadeias equivocadas de ficções a que se recorre para explicar o mundo e governar os homens. Mas os signos não se restringem a configurar mentalmente essas manchas de sombra que são as afecções de um corpo a outro corpo. Na verdade, a 
afecção, ao repercutir-se como afecto, altera o corpo afectado, aumenta ou reduz a potência com que este operava. O registo imaginativo é simultaneamente um registo afectivo. Donde, as 'ideias da imaginação' não podem considerar-se apenas como simples erro e encarar-se unicamente como ausência de verdade. O ser da substância é, de facto, este inter-agir dos seus modos que se exprime afectiva e imaginariamente, não uma hipotética e insondável latência por detrás da ilusória consistência das sombras. (AURÉLIO, 2000, p. 25).

Este tipo de representação, portanto, diz respeito ao modo como um corpo interfere no outro. No entanto, passa por dizer respeito à essência do próprio corpo e, por isso, é "inadequada". Ela separa a consequência da causa; porém:

[...] a verdade é que a experiência, opinião ou imaginação ... se apresenta como estruturada e coerente, reconduzindo a multiplicidade à unidade sob a forma de universais, ainda que estes sejam ideias gerais, abstracções, figurações ou narrativas. Seja quando opera a partir de noções comuns, isto é, quando raciocina, seja quando opera a partir de experiências particulares, a mente articula da mesma forma discursiva ou argumentativa - os seus dados. A diferença está em que, no primeiro caso, a mente opera segundo princípios constitutivos da sua própria natureza, os quais estabelecem o verdadeiro e o falso independentemente dos objectos que possam existir fora dela, enquanto no segundo caso a mente reproduz os objectos e os acontecimentos que se dão no seu exterior tal como eles lhe aparecem e tomando esta aparência por uma realidade. (AURÉLIO, 2000, p. 91).

Dois séculos mais tarde, Friedrich Nietzsche - para quem espinosanamente nem tudo de útil seria verdadeiro - ecoará o autor do Tratado Teológico-Político em tom característico:

Todo conceito se origina de igualarmos aquilo que é desigual. Nenhuma folha é totalmente igual a outra, e o conceito 'folha' é formado por uma abstração arbitrária dessas diferenças individuais, esquecendo-se as distinções; e, então, isso dá origem à idéia de que, na natureza, 
possa haver algo mais além das folhas, que seria 'folha' ... as verdades são ilusões das quais esquecemos o que são; metáforas que se gastaram e a seu poder sensorial ... ser veraz significa usar as metáforas costumeiras em termos morais: a obrigação de mentir de acordo com uma convenção fixa, de mentir como em rebanho, em um estilo obrigatório para todos. (NIETZSCHE, 1980, p. 46 - 47).

A profecia nas Escrituras, tal como finamente analisada por Espinosa no seu Tratado Teológico-Político, seria um caso exemplar do sistema de percepção através da imaginação, denominado de conhecimento do primeiro gênero. E aqui talvez seja preferível darmos a palavra ao próprio filósofo, no primeiro capítulo deste seu livro, para que fique claro o quanto estava longe de querer fazer uma simples denúncia da imaginação:

Pode-se, pois, afirmar agora sem quaisquer reticências que os profetas não perceberam a revelação divina senão através da imaginação, isto é, mediante palavras ou imagens, as quais ora eram reais, ora imaginárias. Na verdade, se não encontramos na Escritura outros meios além destes, também não nos é licito, conforme demonstramos, estar a inventá-los. No que toca, porém, às leis da natureza segundo as quais tal aconteceu, confesso que as ignoro. Poderia, evidentemente, dizer, como outros fazem, que é em virtude do poder de Deus, mas isso não passava de conversa fiada. Seria o mesmo que querer explicar a forma de qualquer coisa singular por um termo transcendental. De facto, tudo é feito pelo poder de Deus, e, além disso, na medida em que o poder da natureza não é senão o próprio poder de Deus, nós não compreenderemos este enquanto ignorarmos as causas naturais. É, portanto, insensato recorrer a ele quando ignoramos ainda a causa natural de qualquer coisa, que o mesmo é dizer, o próprio poder de Deus. Verdadeiramente, nem sequer é preciso sabermos qual a causa do conhecimento profético; como já disse, o que tentamos aqui analisar são apenas os ensinamentos das Escrituras, para deles extrairmos, como se se tratasse de dados naturais, 
as nossas conclusões. Quanto às causas de tais ensinamentos, essas não nos preocupam.

Tendo, portanto, os profetas percebido pela imaginação o que Deus lhes revelou, não restam dúvidas que eles poderiam ter percebido muitas coisas que excedem os limites do entendimento, pois com palavras e imagens se podem compor muito mais ideias do que só com os princípios e as noções em que se baseia todo o nosso conhecimento natural.

É, além disso, evidente a razão por que os profetas perceberam e ensinaram quase tudo por parábolas e enigmas e exprimiram sob forma corpórea todas as coisas espirituais: é que, assim, as coisas adequam-se melhor à natureza da imaginação. (ESPINOSA, 1988, p. 134).

Deleuze explicará em aula que, para Espinosa, o profeta é o marco por excelência de quem opera numa dimensão simbólica e que o profetismo "[...] é o ato pelo qual recebo ou creio que recebo um signo e pelo qual emito signos"; e onde não há expressões, como seria "no mundo tal como ele é" quando, aí sim, signos é que não há (DELEUZE, 2015, p. 192). Razão e imaginação, portanto, possuiriam naturezas diferentes e ao imanentismo junta-se um forte realismo, que contrasta com uma elaboração construcionista no plano da representação imaginária. No entanto, no que diz respeito tanto ao primeiro gênero (o das experiências particulares), quanto ao segundo (o das noções comuns), ambos se equacionam à luz da mútua determinação dos corpos (AURÉLIO, 2000), o que lhes empresta uma afinidade. A imaginação em sua passividade:

[...] é um género de conhecimento, um processo mental [...]. As suas ideias resultam da receptividade da mente, mas nem por isso deixam de constituir sempre uma síntese da multiplicidade das afecções, seja através dos processos integradores da memória, seja através de noções gerais e abstractas, como o tempo, o número e a medida, os quais servem de "auxiliares da imaginação" (AURÉLIO, 2000, p. 219). 
Contudo, na mesma carta a L. Meyer em que trata desses auxiliares da imaginação, é bom lembrarmos, Espinosa marca os seus limites enquanto "maneiras de imaginar" e "seres de razão", pois: "[...] há muitas coisas, com efeito, que não podemos apreender a não ser pelo entendimento, e não pela imaginação, como, entre outras, a substância e a eternidade [...]" (SPINOZA, 2014, p. 81). Isso absolutamente não deixa de conceder à imaginação a estatura de uma poiética e um imenso espaço para o seu exercício que incluiria também a política, inseparável dela.

\section{Presságios e sonhos}

Entre as cartas deixadas por Espinosa, há uma que trata dos presságios. Foi escrita em resposta ao seu amigo menonita e colegiante Pieter Balling e contém uma curiosidade de especial interesse para leitores brasileiros, a qual se soma à sua suposta ascendência lusa, detectável esta - segundo especialistas - inclusive por indícios em seu próprio latim. Balling havia se referido ao fato de, em certa época, ele ter ouvido gemidos semelhantes aos que posteriormente o seu filho viria a emitir ao adoecer e, a seguir, morrer. Espinosa afirma, então, tratar-se isto de produto da imaginação liberta de Balling, posto que este não ouviu os referidos gemidos ao buscar mais atentamente escutá-los. Ele passa, então, em um raro momento de autorreferência íntima, a relatar um episódio ocorrido com ele próprio alguns meses antes, no inverno:

Certa manhã, quando o céu já se aclarava, ao despertar após um sonho muito penoso, as imagens que se me apresentaram no sonho ofereceram-se aos meus olhos com tanta vivacidade como se fossem objetos reais, em particular as de um certo brasileiro negro e escabioso que eu jamais tinha visto antes. Essa imagem desaparecia na maior parte quando, para me aliviar, eu fixava meu olhar em um livro ou em algum outro objeto, mas tão logo eu desviava os olhos daquilo e cessava de mirar atentamente o que quer que fosse, a mesma imagem do mesmo negro reaparecia com a mesma vivacidade repetidas vezes até que, pouco a pouco, ela desapareceu do campo visual. (SPINOZA, 2014, p. 99). 
Espinosa explica, então, que os efeitos da imaginação nascem da constituição do corpo ou da alma e que quando, como no caso de Balling, a imaginação está na dependência da constituição da alma:

\begin{abstract}
[...] ela segue em tudo os rastros do entendimento, encadeia e ordena suas imagens, como o entendimento de suas demonstrações; de modo que nós não podemos conhecer pelo entendimento quase nada do qual a imaginação não forme, em seguida, uma imagem. ... os efeitos da imaginação ou imagens que tiram sua origem da constituição da alma podem ser presságios de qualquer coisa futura, porque a alma pode sempre pressentir confusamente o que será. Ela pode, portanto, imaginá-lo tão nítida e vivamente como se um objeto da mesma espécie estivesse presente. (SPINOZA, 2014, p. 100).
\end{abstract}

A seguir, ele detém-se no caso da relação pai-filho tal como lhe fora apresentado, afirmando que, em face da qualidade amorosa desta relação, eles "não formam mais do que um único e mesmo ser"; a alma do pai participando da essência ideal do filho de tal forma que lhe permite "imaginar por vezes qualquer das coisas que dela decorrem tão vivamente como se elas se apresentassem a ele próprio" (SPINOZA, 2014, p. 100). E passa a enumerar as condições para que tal se dê, tais como: o caráter notável do evento, que este seja fácil de imaginar, que não haja grande distância no tempo e que o corpo esteja livre de preocupações que possam perturbar os sentidos; e, eventualmente, que os objetos presentes no pensamento evoquem imagens semelhantes na memória (SPINOZA, 2014).

No episódio que se passou com Espinosa, não houve aparentemente presságios, mas, na medida do possível, seria interessante buscarmos alguma contextualização que o próprio sonhador não fornece, deixando-nos na ignorância quanto a se e como ele faria a mesma associação sugerida a seguir. A missiva é datada de julho de 1664. O domínio holandês no atual Nordeste brasileiro estendera-se de 1630 a 1654, sendo oportuno recordarmos que Espinosa, nascido em 1632, teria, portanto, vinte e dois anos quando da expulsão definitiva. Nessa expulsão, como sabemos, 
houve participação significativa dos negros. Tal domínio fora projeto da Companhia Holandesa das Índias Ocidentais, à qual se associava intimamente a colônia judaica de Amsterdã - inclusive, o pai comerciante de Espinosa, com o qual ele trabalhara na juventude e que teria possuído na época uma fazenda em Pernambuco. Acrescentemos que um dos expulsos quando do abandono do Recife foi o rabino cabalista Isaac Aboab de Fonseca, antigo professor de Espinosa, que viria mais tarde, em 1656, a ler em público o herem (documento de excomunhão) que o excluiu da congregação luso-espanhola judaica de Amsterdã, juntamente com a numerosa colônia judaica - em boa parte proveniente de expulsão anterior da península Ibérica - e que controlava metade do comércio de açúcar e de escravos (GONZÁLEZ VARELA apud MARX, 2012). Aboab de Fonseca - português da Beira Alta - foi o primeiro rabino praticante nas Américas na sinagoga criada em Recife, em 1636, tendo sido colega de outro professor de Espinosa, Menassé ben Israel, autor de vários livros considerados importantes (SPINOZA, 2014). Ben Israel viria a ser ele próprio excomungado em 1640 por criticar a Companhia das Índias, da qual era acionista, à maioria dos membros do conselho que julgou Espinosa (DELEUZE, 1981).

Até aqui, se poderia dizer estarmos no terreno do entendimento, tal como apresentado por Espinosa na mesma carta. Contudo, desse entendimento, segundo ele, a imaginação "segue em tudo os rastros", as imagens sendo encadeadas como se fossem demonstrações. E aí chegamos à figura central, a do "certo brasileiro negro e escabioso", como González Varela nos informa:

A sua narração deste sonho obsessivo com os olhos abertos tem sido debatida pelos especialistas. Foi identificada com o escravo negro rebelde Henrique Dias, líder de uma revolta contra os holandeses na cidade de Pernambuco [sic], Brasil, entre 1645 e 1648, uma guerra defensiva chamada Guerra da Luz Divina. [...]. Dias tinha o título popular de "Governador dos crioulos, pretos e mulatos do Brasil". [...]. Toda a Holanda quedou-se comovida com esta guerra colonial e Espinosa duplamente afetado e confundido: pelos negócios de seu pai na fazenda que tinha em 
Pernambuco e pela expulsão do Brasil de seu antigo professor de doutrina [...]. (GONZÁLEZ VARELA apud MARX, 2012, p. 256n).

Não foi possível verificarmos a que especialistas se refere González Varela, mas a plausibilidade da hipótese é inegável. Em texto anterior (VELHO, 2019b), dissemos que Espinosa (assim como Nietzsche) era "deslocado" em relação ao seu tempo e lugar, mas também que isto se referia a um lado seu. Aqui o que surge é justamente o outro lado: um Espinosa solidário com os seus conterrâneos holandeses - os quais teriam quedado comovidos com esta guerra colonial - e até com a comunidade judaica e a família, com as quais rompera. Quanto à sua relação fisicamente distante da família e da comunidade, Johannes Colerus, seu primeiro biógrafo, já chamara a atenção, no começo do século XVIII, para o fato de a sua dedicação à arte de polir lentes estar de acordo com os preceitos judaicos, os quais recomendavam, seguindo a Lei e os antigos doutores: "que não é bastante ser sapiente, mas que, além disso, deve-se exercer uma arte mecânica ou profissão" (COLERUS apud SPINOZA, 2014, p. 328).

Esta solidariedade se daria em um nível subconsciente, mas a ponto de, com o olhar de hoje, podermos considerá-lo por este lado profundo, parte inegável de um contexto colonialista e racista, que juntamente com a misoginia, mereceriam atenção para verificar eventual efeito de distorção ou limitação sobre a obra de Nietzsche - contanto que não caiamos em um anacronismo ou presentismo reducionista. Se de fato, como afirmava o seu sonho, não tinha também caráter premonitório, como o de Balling, poderia ser - como já nos foi sugerido - uma forma de lidar com o aspecto monstruoso e insidioso da escravidão? Nessa linha, talvez acabasse por ser de fato um presságio, na medida em que a sua conexão (intelectual) profunda com a república moderna produzisse essa aparição significativa de matiz profético: a revelação de que a racionalidade da ordem civil não redime as explorações de tipo colonial. Nesse sentido, seríamos levados ao reconhecimento de que Henrique Dias, enquanto representante imaginativo das populações afro-indígenas de todos os matizes e matrizes, seria um aliado possível, natural, para "renaturar" a república. 
Ainda quanto à figura do "brasileiro negro e escabioso", vale a pena registrarmos a existência na Holanda, ainda nos dias de hoje, de uma festa celebrada no dia de São Nicolau, em 5 de dezembro, e nas semanas que o precedem, tendo a participação de um personagem de suposto auxiliar de São Nicolau, denominado Zwarte Piet (em inglês Black Pete). Este auxiliar é apresentado como sendo negro (mas, por vezes, também mouro, vindo ele da Espanha) e há o costume de as pessoas se fantasiarem pintando o rosto de preto. A festa é muito popular, mas, nos últimos anos, tem crescido a oposição a ela, com maior adesão entre a população negra (sobretudo a vinda de Gana, Antilhas e Suriname), chamando-se então a atenção para o seu caráter racista e colonial, sobretudo por estereotipar o negro e retratar uma situação de subserviência diante do branco. A oposição, no entanto, não se restringe aos negros e tem crescido no bojo dos movimentos Vidas Negras Importam (Black Lives Matter). Os defensores da festa, por sua vez, distribuem-se entre os que alegam não verem nenhuma conotação racial ou colonial nela e os que mais afirmativamente a defendem como parte de uma herança cultural e da nacionalidade, sendo que, entre esses últimos, encontram-se grupos de supremacistas brancos e neonazistas. Seja como for, é interessante registrarmos a persistência de uma figura similar à que Espinosa viu em sonho - na verdade, um pesadelo - e a sua associação a controvérsia raciais em um país envolvido com a escravidão e o tráfico de escravos até 1863.

Retornando ao sonho acordado (ou lúcido) de Espinosa, por fim, vale a pena registrarmos também que Susan James em livro sobre o Tratado Teológico-Político faz justamente a conexão entre este e a profecia estudada no próprio Tratado: "[...] assim como a imagem do brasileiro por Espinosa era vívida e duradoura o suficiente para fazê-lo duvidar que ele tinha sonhado, algo semelhante explica a imagem de Deus por Moisés, estando acordado" (JAMES, 2012, p. 47). E quanto à relação entre o presságio (de Balling exemplarmente) e a profecia, assim ela escreve, seguindo Espinosa: 
[...] o modo de compreender a revelação é percebê-la como o resultado de uma capacidade imaginativa que todos os seres humanos possuem em algum grau. Os profetas eram de fato extraordinários; mas o que os fazia assim era a qualidade fora do comum de suas imaginações, que lhes dava acesso a insights que estavam além do alcance de pessoas mais ordinárias. (JAMES, 2012, p. 49).

Porém, ainda seguindo e resumindo eficazmente o autor do Tratado Político-Teológico, diz a autora que os "dons da imaginação não são em geral acompanhados por capacidade excepcional de raciocínio" e, inversamente, "aqueles mais capazes no seu intelecto [...] têm um poder mais moderado de imaginar" (JAMES, 2012, p. 50), como seria exemplarmente o caso de Salomão. Ao assim separar o dom profético da sabedoria do conhecimento em matéria natural e espiritual, Espinosa contrapunha-se a Maimônides e a outros pensadores (JAMES, 2012).

\section{0 imaginário e suas vulnerabilidades}

Se fosse o caso de pinçarmos, em Imaginação e Poder, uma única frase que sintetizasse o significado do livro para os propósitos deste texto, poderia ser a seguinte: "O que define a imaginação é o ser um conhecimento diferente, não um conhecimento inferior" (AURÉLIO, 2000, p. 221). A isso poderíamos agregar na definição dessa diferença: "O que daí se adivinha é a lógica do subconsciente, o que já se desvenda é a potência do imaginário" (AURÉLIO, 2000, p. 222).

Conhecimento diferente, sendo inútil especular como se os homens pudessem deixar de ser o que são. Conhecimento passivo, construído a partir de determinações externas. Portanto, é vulnerável a essas determinações, mas demonstra a sua potência nos presságios, nas profecias e até em um sonho como o de Espinosa. Esta parece ser a chave que nos fica para pensar, justamente, aquilo que nos rodeia e nos determina na vida prática e cotidiana, já que, em nosso tempo, essa tarefa tem sido reservada preferencialmente às "ciências humanas e sociais". 
Essas ciências poderiam duvidar da pertinência dos escritos de um filósofo seiscentista para a compreensão do que vivenciamos hoje e do que indicamos no início do texto. No entanto, no que diz respeito ao imaginário, não será exatamente de conectividade, redes sociais e suas afetações que tratamos sempre, independentemente do meio, modalidade e escala? Evidentemente, não queremos subestimar a necessidade de buscarmos conhecer profundamente os desafios da atual "sociedade de risco"; os novos recursos, não só tecnológicos, mas também os da exploração capitalista na transformação da própria tecnologia em principal fator de produção, juntamente com o conhecimento livre de suportes materiais; bem como os recursos culturais representados por correntes de pensamento assertivas, como no caso das modas e dos palpites (informados e/ou desinformadores), disseminados em massa. Pelo menos, valeria a pena vermos até onde poderíamos ir nesta trilha como modo de neutralizar nosso estreito progressismo. Inclusive para introduzir no debate sobre redes a questão da vulnerabilidade.

A mensagem central que aqui queremos apresentar é a de que é preciso não confundir a lógica da imaginação com o eventual produto de suas vulnerabilidades, inclusive das manipulações a que havíamos feito referência no início e a que agora retornamos. Precisando: as fake news e suas congêneres não são estranhas à imaginação, mas também não a esgotam ou condenam. O movimento antivacina, por exemplo, pode possuir entre os seus argumentos alguns que deveriam ser respeitados ou mesmo considerados no contexto de discussões em um ambiente democrático. No caso histórico da Revolta da Vacina, que já mencionamos, é reconhecida hoje a violência física e psicológica a que a população foi submetida. O potencial de dano das vacinas também é reconhecido, sobretudo - na voz da própria comunidade científica internacional - se os padrões regulatórios forem contornados, assim como são - ou deveriam ser - reconhecidos os interesses comerciais e políticos. No entanto, há vidas em jogo e o próprio movimento pode ser manipulado ou se tornar manipulador, como quando, por exemplo, é associado à proliferação de fake news sobre possíveis imunizantes contra o novo coronavírus. Isso depende de quem assume essa bandeira e com que finalidade, eventualmente adentrando o terreno das "teorias da conspiração", 
teorias afins das vulnerabilidades do imaginário, por via de uma "sabedoria popular" que, oriunda de experiências particulares, porém marcantes, seguidamente contempla a figura do bode expiatório. Essas experiências vêm a fixar desconfianças e temores em relação ao desconhecido ou às instituições e sua persistência comprova a permanência do estado de natureza em uma situação em que a interdependência social teoricamente consolidada não deixa de ser flutuante (AURÉLIO, 2000). Aliás, tais desconfianças e temores, muitas vezes, são confirmados de uma maneira ou de outra; hoje estão na base de noções orquestradas que vicejam na internet e alhures, como as acusações de suposta disseminação solerte do marxismo cultural, do politicamente correto, da prática da pedofilia, entre outras, e envolvendo a utilização corriqueira de agressões virulentas. É possível mesmo argumentarmos - sem que isso negue as possibilidades democratizadoras da cultura digital - que, à luz da teoria espinosana da imaginação, " [...] em que a percepção que temos dos corpos exteriores indica mais a natureza do nosso corpo do que a dos corpos que nos afectam, a diferença entre percepção e alucinação tende a esbater-se, sendo mesmo 'nula' do ponto de vista psicológico" (AURÉLIO, 2000, p. 272).

Na questão da Besta-Fera, por sua vez, esta figura pode ser acionada por todos os lados em um jogo político que a própria ideia usual de manipulação talvez não capte em sua inteireza. Seria preciso, efetivamente, nesses e em outros casos, focarmos essas vulnerabilidades distinguindo seus produtos diversos. No caso da "manipulação", desde as décadas de 1920 e 1930, por exemplo, sem dúvida os movimentos e os Estados fascistas já haviam feito as atenções se voltarem para a propaganda política de que - avant la lettre - as fake news faziam parte. Esse foi o caso verdadeiramente alucinatório da notícia espalhada entre as tropas italianas, no final da Segunda Guerra Mundial, de que os comunistas comiam seres humanos, o que não deixa de suscitar associações com casos mais próximos, inclusive o da Besta-Fera, além de diversas outras versões da mesma história, associadas ou não, e em grau variado, à propaganda no seu sentido estrito. A propaganda política parece plenamente calcada no primado de afetos/ afecções e na busca de vulnerabilidades. Nisso ela não difere da variante comercial da publicidade e sua noção de marketing, mas 
também de sentimentos e atitudes persecutórios não necessariamente produtos de manipulação. A “boa” manipulação (política, comercial ou mesmo religiosa), também apelidada atualmente de tecnologias de persuasão, na verdade parece ser aquela capaz de captar desejos e temores desse gênero e devolvê-los, ampliados, repetidas vezes; como o são os envolvidos na busca de soluções imaginárias ou efeitos de consolo para problemas não resolvidos na política, por exemplo. Isso se dá igualmente no preenchimento da lacuna deixada pelos tempos da própria ciência na produção de vacinas contra o novo coronavírus, o que não deixa de ter a sua lógica. Por isso, nem sempre é fácil distingui-la (a manipulação) sem que essa própria busca se torne persecutória-alucinatória ou simplesmente desfocada.

É possível que nos faltem outras referências para abordar este assunto. Ainda no que diz respeito à década de 1930, é bom lembrarmos a mais espetacular fake news de então: a encenação radiofônica da ficção científica de H. G. Wells, Guerra dos Mundos, feita em 1938 por Orson Welles, e os efeitos de pânico generalizado por ela suscitados. Além de sugerir que ampliemos o entendimento do que seriam os "novos" recursos tecnológicos, isso sugere ainda uma analogia teatral: o teatro, que justamente se especializa em mexer eficazmente com o subconsciente, incorpora-se no rádio, que revelou já naquela época, de modo poderoso, o potencial propagador das "novas tecnologias". O argumento, aqui, vai justamente no sentido de ser preciso voltarmo-nos para a imaginação e os seus auxiliares e, ao mesmo tempo, focá-la de uma forma mais ampla, acolhendo neste referencial a compreensão de comportamentos inesperados e aparentemente irracionais, retirando-os do terreno do inexplicável. A própria irracionalidade precisaria ser entendida como reação a uma racionalidade desapegada da natureza e incapaz de dar conta dos movimentos do real. Essa reação pode chegar a afirmar-se e exacerbar-se como tal em homenagem à irredutível contingência em que opera o imaginário e que - em contraste com o que se dá no mundo da propaganda - seguidamente escapa às ciências humanas e sociais (VELHO, 2019b); no caso destas, não por deixarem de registrar essa contingência, mas por nem lhe atribuírem um estatuto teórico, nem saberem lidar com ela na prática. 
Tudo isso faz-nos ansiar pelo terceiro gênero de conhecimento acenado por Espinosa como sendo o de retorno à ênfase na particularidade própria da imaginação, mas agora acompanhada de uma compreensão da natureza como "única forma de evitar que a actuação seja mera conseqüência das afecções" (AURÉLIO, 2000, p. 226). Isto vai na direção de uma libertação, no entanto inalcançável em sua plenitude. Este tema da libertação - em contraste com o cativeiro típico da passividade e da hetero-afecção em que estamos imersos e onde a "manipulação" deve ser situada em sua proporção devida - parece ser retomado por Nietzsche dois séculos depois com as noções de "demasiadamente humano" e de "sobrehumano". Essa retomada, por sua vez, expressa uma contestação à linearidade na história do pensamento que, no presente texto, é reafirmada e por ela justificada.

No que diz respeito ao "demasiadamente humano" - o que nos ocupa no momento -, vale a pena uma nota de encerramento desta parte da argumentação, lembrando a proposição VII da quarta parte da Ética, que, mais de três séculos depois, não parece ter sido plenamente assimilada pelos "filósofos" e racionalistas de nossa época, o que constitui mais um indício - no caso, até a se lamentar - contrário à linearidade do pensamento: "Um afecto não pode ser reprimido, nem suprimido, a não ser por um afecto contrário e mais forte do que o afecto a reprimir" (ESPINOSA, 2020, p. 275).

Argumentações racionais em casos como este são de pouca valia e transformar o "pensamento crítico" em divisor de águas significa, em termos espinosanos, uma incompreensão da natureza do que está em jogo, já que diretamente é esta que rege a existência e não a razão.

\section{Estado de natureza}

Em texto recente, fizemos menção a um "além do social" (VELHO, 2020). Esta imagem pretendeu, entre outras coisas, chamar a atenção para a postura espinosana segundo a qual o estabelecimento de um poder soberano não implica o abandono de um estado de natureza (bom para pensar) em troca de um estado civil ou político. O "além" sugeriria, em direção diversa, a 
superação de uma oposição entre sociedade e natureza derivada da tradição hobbesiana e, com ela, a superação da própria noção de sociedade tal como foi construída nesta tradição, segundo a qual não haveria sociedade politicamente organizada anterior ao estabelecimento de um poder soberano (AURÉLIO, 2000). Seguindo esta linha alternativa, as ditas ciências humanas e sociais deveriam necessariamente se reconhecer como ciências da natureza; tal como, aliás, já tem sido indicado em antropologia na obra de autores seminais - embora, de modo sintomático, ainda relativamente marginais no interior da disciplina - como Gregory Bateson e Tim Ingold (VELHO, 2018c). Esta superação poderia, inclusive, finalmente reconciliar plenamente as "sociedades primitivas" sem ou contra o Estado - e a teoria social.

Quanto ao Estado propriamente, segundo esse ponto de vista, mantém-se, pois, flutuante e em uma tensão de forças a interdependência entre governantes e governados, de forma não consolidada, racional e garantida por um princípio transcendente. Tudo se passa no plano da imaginação e do jogo passional, sendo a vontade de poder derivada do esforço para continuar a existir e, portanto, um direito de natureza (AURÉLIO, 2000). Aqui não estamos nos detendo na evolução do próprio pensamento de Espinosa - por exemplo, entre a redação do Tratado Teológico-Político (ESPINOSA, 1988 [1670]) e a do posterior e inacabado Tratado Político (ESPINOSA, 2011) -, que é objeto de elaboradas discussões entre os especialistas.

A soberania é constituída pela potência da multidão, mesmo na figura da vontade de obediência, e esta potência subjaz a todas as formas de poder constituído; na verdade, o poder constituinte jamais se esgotando. Não há propriamente transferência de direitos ao soberano, mas uma conjugação de potências e a multidão: “[...] é simultaneamente a força agregadora que se exprime como potência do uno e a força desagregadora que se exprime como multiplicidade, conflito e inconstância de interesses" (AURÉLIO, 2000, p. 276).

A consequência desta configuração paradoxal é a fragilidade do Estado político, distante do Leviatã de Hobbes e seu ponto de apoio externo. Isso não significa que não haja a formação de um 
arcabouço legitimador do poder que ignore ou faça por ser ignorada a sua própria imanência, seja na figura de um Deus - tal como Espinosa examinou no Tratado Teológico-Político para o caso hebreu - seja nas suas sombras, como Pátria. Mesmo considerando tal arcabouço como uma "superstição", Espinosa não pretende substituí-lo pelo primado da razão. E. Balibar, citado por Aurélio (2000, p. 310), chega a sugerir que uma verdadeira religião deva na verdade constituir-se como uma "superstição civil". É assim que se constitui a própria política como parte inextricável do imaginário. Aurélio, citando o Tratado Teológico-Político, sintetiza as implicações dessa configuração dinâmica em contexto de democracia, de um modo que guarda atualidade para nós:

Sem dúvida, a passionalidade das multidões torna-as cativas dos preconceitos, manipuláveis por teólogos intolerantes e arrastadas por ambiciosos que atentam contra a segurança e o bem-estar colectivos. Exigir ao Estado que garanta a liberdade de opinião pode, além disso, representar a prazo a entrega perante um qualquer autoritarismo, portador de coesão mas liberticida. É um risco, e Espinosa sabe-o, mas sabe também que um tal governo, a prazo, está votado ao descalabre. Os poderes soberanos possuem, obviamente, 'o direito de considerar como inimigos todos aqueles que não estiverem de acordo consigo em todas as matérias' [Espinosa 1988, cap. XX]. Contudo, uma vez que 'é impossível tal procedimento sem pôr em grave risco todo o Estado, podemos até negar que eles tenham o poder e, por conseguinte, o direito de actuar desse modo. Na verdade, conforme já demonstrámos, o direito dos poderes soberanos é determinado pela sua potência' [Espinosa 1988, cap. XX]. (AURÉLIO, 2000, p. 287 - 288).

E, por fim, quanto à imaginação no âmago desse processo:

Longe de se reduzir apenas a um conhecimento 'mutilado', por não incluir as verdadeiras causas, a imaginação revela-se uma expressão e um instrumento do desejo, o qual não é senão a essência do homem enquanto 'apetite consciente', vontade de perseverar na existência. (AURÉLIO, 2000, p. 335). 


\section{A ciência e suas vulnerabilidades}

Como vimos na questão da soberania, a superação da concepção hobbesiana significa que tanto súditos quanto soberanos - ou os seus equivalentes modernos, governantes e governados - permanecem no "estado de natureza". Como sintetiza Aurélio (2000, p. 268), é a natureza que "transfigura-se em lei". Fosse outro o recorte, apesar do seu exercício privilegiado da razão, os cientistas, movidos pela potência de agir e o exercício da "vontade de perseverar na existência", estariam igualmente abarcados nesse mesmo estado de natureza, imersos - embora não exclusivamente - no plano da imaginação, o que também não confundimos com uma pura passionalidade desordenada e despida de racionalidade na sua própria oscilação.

Acima utilizamos um sonho de Espinosa para acentuar a universalidade do imaginário. Mas, no mesmo espírito espinosano de compreensão, o que dizer dos cientistas, esses atores que se tornaram estratégicos nas discussões públicas contemporâneas? Afinal, Einstein também sonhava acordado, o que, aliás, parece pôr em dúvida serem os mais capazes em intelecto menos capazes de imaginar. É muito delicado falar desapaixonadamente deles num momento em que são erigidos à posição de heróis na defesa da racionalidade, em uma situação política e epidemiológica extrema e em pleno agravamento da crise climática, tudo isso dando margem a "negacionismos" diversos.

Essa dificuldade é agravada quando somos partícipes deste jogo e há boas razões políticas e afetivas para não querermos estragá-lo. Por isso, não há como deixarmos de ser econômico neste tópico, que, no entanto, se impõe. É essa economia que também nos leva a tratá-los em bloco, sem privilegiar a distinção entre grandes áreas do conhecimento. Para este tratamento em bloco, no entanto, há também uma justificativa substantiva, que tem a ver com o fato de existir - estamos falando de nosso caso nacional um espírito corporativo que efetivamente une a chamada "comunidade científica". Este espírito nem sempre é evidente no dia a dia, mas assoma com força em momentos de crise, momentos que em geral se definem por ameaças ao funcionamento da atividade científica, seja para a sua reprodução simples, seja para a 
ampliada. É quando, então, podemos utilizar recursos já construídos e presentes o tempo todo, tais como as já mencionadas associações definidas por uma identidade transversal - quais sejam, a SBPC e a ABC - e as posições ocupadas no aparato governamental latu sensu por representantes da comunidade. Estas posições incluem tanto as definidas formalmente como nos conselhos de várias ordens, quanto as ocupadas por membros da comunidade em função governamental executiva, não sendo difícil observar que estes executivos funcionam também como representantes da comunidade e, em muitos casos, são escolhidos por governos justamente devido à sua atividade anterior nas associações científicas. Também é fácil observar que não funcionam isoladamente, mas se organizam em redes de relações importantes, o que na verdade parece sugerir que não só eles, mas a própria comunidade enquanto tal - que os tem como seus representantes - constituem a configuração de uma espécie de indivíduo coletivo.

Qual seria, então, no plano do imaginário, a referência unificadora? Diríamos que se trata, justamente, de uma entidade denominada Ciência, o respeito pela qual, entre outras coisas, indubitavelmente indica uma postura de gratuidade e mesmo de reverência garantidora do padrão predominante de inteireza profissional. Esta Ciência é definida em geral não substancialmente, mas por procedimentos: metodologias, protocolos de pesquisa e de sua confirmação, normas de avaliação para efeitos de publicação, controle da lisura profissional e outros. É a partir daí que se estabelecem as fronteiras de pertencimento, embora na prática saibamos que há uma flexibilidade na observância desses procedimentos que os sociólogos da ciência já detectaram. Em geral, tirante essas questões, substantivamente as diversas áreas de pesquisa são respeitadas em sua identidade própria, a liberdade de pesquisa sendo um valor a ser preservado como parte essencial da Ciência, porém criando zonas de atrito com as ciências humanas e sociais: não por acaso, a aceitação destas na $\mathrm{ABC}$ foi muito tardia.

A Ciência possui, para seus participantes, um poder imagístico que se aproxima do de uma sombra transcendental. Em nome dela, por exemplo, podemos aceitar recursos de fontes política e/ ou ambientalmente incorretas enquanto isso puder ser feito sem 
comoção pública (VELHO, 2018a). Contudo, isso também faz com que haja preocupação com a reprodução da atividade científica para além das carreiras profissionais individuais, donde um interesse genuíno pela educação e um verdadeiro espírito de missão, que se estende por outras áreas. Esse interesse se dá não só em relação à educação científica, mas também ao crescimento em escala da massa de educandos, de modo a garantir uma base do tipo "quanto maior, melhor" para a seleção de talentos e vocações. O elã pela Ciência é tal, alcançando inclusive indiscutível dimensão estética e emotiva, que em geral internamente a questão da aplicabilidade ou dos "resultados práticos" não parece sensibilizar muito ou ter prioridade. Ganha-a, aparentemente, na medida em que se torna crucial no enfrentamento com o mundo exterior. Mesmo aí, o esforço é grande para garantir a necessidade de uma "ciência básica", ajustando-se a imagem para sugerir sua indispensabilidade como condição para as aplicações que são demandadas por governos, empresários, movimentos sociais e leigos em geral. Quanto às aplicações, propriamente - ou "inovações", nos últimos anos -, a estratégia consiste no artifício de apresentar sempre os mesmos exemplos para legitimar o conjunto da Ciência.

As ocasiões de crise com o mundo exterior - em geral, o governo - são momentos de reajuste e, desse ponto de vista, podem ser eventualmente oportunidades, havendo também momentos de oportunidade não necessariamente associados a crises. São sempre, no entanto, momentos em que critérios advindos de fora precisam ser absorvidos ou rejeitados, havendo o risco de divisões internas a respeito. O biólogo e escritor Henri Atlan preocupa-se muito com o uso ideológico da ciência, por exemplo, quando teorias científicas bem aceitas e consideradas prováveis são apresentadas ao público como certezas, podendo os próprios cientistas ter certa "quota-parte de responsabilidade" nisso, por via de um "triunfalismo científico" (ATLAN; BOUSQUET, 1996, p. 168; 184). Em contrapartida, ele se inquieta com uma reação ao cientismo que faz cair "num irracional ao qual pretendem dar bases científicas" as pseudociências e cita uma pesquisa segundo a qual "50 por cento dos franceses pensam que a astrologia é muito importante para a sua saúde, e chegou-se ao ponto de um certo número de médicos 
terem se convertido à astrologia" (ATLAN; BOUSQUET, 1996, p. 176). Quanto a fenômenos como este, é inegável que ir contra a ortodoxia científica na busca de uma solução para a ansiedade advinda de uma situação de aflição parece efetivamente exercer um fascínio público considerável, tal como em supostas "descobertas" para a cura do câncer, que já se manifestaram entre nós e, mais recentemente, nas controvérsias envolvidas na utilização da cloroquina. Poderíamos falar também, amplificadamente, do estado existencial de insegurança e da sensação de risco mais permanente diante da experiência da incerteza, das mudanças ou de perdas, sobretudo perante as ameaças do invisível - como os vírus - e a proliferação de opiniões contraditórias vindas de todos os lados e por todos os meios, que tornam impossível a existência de um monopólio discursivo e de legitimidade. Muitas vezes, tal fascínio vem acompanhado de uma crença em conspirações partidas de forças poderosas que teriam como objetivo oculto impedir o acesso a estas curas ou a estas soluções, tudo isto exercendo pressão considerável sobre a Ciência.

Seja como for, o fato é que a própria apregoada e defendida liberdade de pesquisa igualmente faz parte do imaginário. Na prática, os constrangimentos sempre se fazem presentes de alguma forma. Entre nós, a relação direta com o mundo empresarial e a sua lógica do lucro ainda é pequena. Porém, certamente as conexões e redes internacionais de ciência em que estamos crescentemente envolvidos e as próprias pressões governamentais são parte de um contexto em que o capital é dominante e onipresente, infiltrando-se de modo por vezes imperceptível na prática científica em todos os níveis, ainda mais com a transformação atual do conhecimento em fator de produção estratégico. De qualquer forma, o certo é que nem mesmo os cientistas podem escapar ao imaginário, quer por seu próprio envolvimento direto, quer pelas suas afetações inevitáveis. É o que podemos chamar o dilema de Atlan e, juntamente, as vulnerabilidades da Ciência.

Quando os momentos de crise para a Ciência são parte de uma crise política maior, a tendência é a de os cientistas se abrirem para outros setores da sociedade como forma de exercício de sua vontade de perseverar na existência. É o que ocorre em 2020 no 
momento em que este texto é escrito. Isso tem sido feito com rara competência e mesmo generosidade, por exemplo, na defesa das populações ditas tradicionais, especialmente indígenas, também no cerramento inédito de fileiras na defesa das mais visadas ciências humanas e sociais, detectadas então como parte das ciências básicas e não como corpo estranho. Entre os eventos de certa forma surpreendentes do atual período, em círculo restrito chamou a atenção o convite inédito a um "indígena do povo Tukano", na verdade também antropólogo, para participar juntamente com dois acadêmicos ilustres de um webinário da ABC sobre a "preservação da Amazônia através da bioeconomia". Ambos os acadêmicos e também o mediador foram extremamente gentis com o antropólogo indígena, buscando encontrar intercessões que permitissem um diálogo entre a ciência e os saberes indígenas, ao mesmo tempo que apresentando dados e resultados de pesquisa sombrios sobre a situação na Amazônia. Este, porém, foi direto ao ponto da dificuldade para o diálogo, ao declarar que a eficácia de determinadas ervas para efeitos medicinais não se prendia à existência ou não de um princípio ativo, mas sim à observância dos procedimentos associados à sua administração, tais como banhos e abstinência sexual. E aí o impasse ficou evidente.

Haveria certamente muito o que dizer sobre as diferentes epistemologias e seus impasses, mas no momento cabe registrarmos apenas que o exemplo da astrologia sugere que este aparente impasse não se refere exclusivamente à relação com um outro bem caracterizado. Para além das epistemologias e dos temores de Atlan, há sempre presente um cálculo. Crenças (ou saberes?) seculares como esta podem conviver com o recurso à ciência sem maiores ruídos e também como linguagem, podem prestar-se a usos - pois é disso que se trata no plano do imaginário - difíceis de rotular, não cabendo aqui, mais uma vez, combater um afeto com as armas de um pensamento que se pretende crítico. Atualmente, porém, a questão parece ter sido capturada na luta pelo poder, tendo sido erigida uma divisão da sociedade entre partidários e antagonistas da ciência. Quando isso ocorre, de fato, o dilema de Atlan reaparece com toda a força. 
No tempo de Espinosa, os antagonistas dos filósofos eram os teólogos (VELHO, 2019a). Daí podermos dizer, como vimos, que "a passionalidade das multidões torna-as cativas dos preconceitos, manipuláveis por teólogos intolerantes e arrastadas por ambiciosos que atentam contra a segurança e o bem-estar colectivos" (AURÉLIO, 2000, p. 287). Isso talvez retire a carga de ineditismo absoluto do que presenciamos hoje - apesar da realização atual de que "o meio é a mensagem" -, por não devermos subestimar o poder holístico também das igrejas e seitas de então. Um ensinamento inicial espinosano difícil de ser assimilado por cientistas, por lhes ser contraintuitivo e exigir que se vá além do senso comum erudito - também já referido acima -, é que um afeto não pode ser contrariado ou suprimido a não ser por um afeto contrário e mais forte que o afeto a contrariar. No Tratado TeológicoPolítico, Espinosa busca uma solução para o seu tempo, que garanta concomitantemente a segurança e a diversidade. Resumindo, podemos dizer que propõe: a democracia como o regime político mais natural; a plena liberdade de pensamento e de opinião; a necessidade de uma separação nítida entre os domínios do saber e da fé; que o culto não perturbe a paz do Estado; e a aceitação de um ideário cristão mínimo comum, que evite as controvérsias teológicas e faça emergir o saber bíblico por elas recalcado, o qual se resume ao conhecimento da justiça e da caridade.

Estamos aqui em pleno domínio do imaginário e das probabilidades, sem chance de demonstração. Pensando em termos de hoje, o que dizer da relação entre democracia e ciência? Os representantes da comunidade científica têm cumprido o seu dever de casa, defendendo a indissociabilidade das duas, mas como dar conta, então, do fato de a China ter superado pela primeira vez os Estados Unidos em número de artigos científicos publicados? Ou de a Rússia afirmar que produzirá a primeira vacina contra o novo corona vírus, disputando a primazia com a China? Perguntas incômodas, que não costumam ser feitas, não por qualquer insuficiência na capacidade de observação dos cientistas, ao que parece, mas porque na verdade eles sabem distinguir muito bem a sua atividade científica e a política, com exceção paradoxalmente dos cientistas humanos e sociais, menos competentes nesta arte, 
já que seguidamente as duas para eles se entrelaçam irremediavelmente. O que se pode dizer da relação entre ciência e democracia é que, assim como na relação entre corpos em geral, trata-se de uma questão de conveniência e não de eficiência. Nesta medida, ela continua válida. Como é dito na proposição XXVI da segunda parte da Ética: "A mente humana não percebe nenhum corpo exterior como existente em acto, a não ser pelas ideias das afecções do seu corpo" (ESPINOSA, 2020, p. 174).

É inevitável que a ciência faça parte do imaginário popular e o paradoxo é que, nesta linha espinosana, um discurso estritamente científico encontra dificuldade em ser ouvido, sendo adicionalmente desejável evitar cair na tentação do "triunfalismo científi-

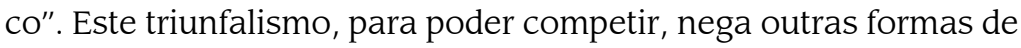
saber e sua própria natureza finita, provocando reações ao pretender dar resposta a todas as questões da existência sem capacidade de escuta ou de incorporação de outros pontos de vista e parcerias. Isso parece ter ocorrido ainda nos anos 1920 e 1930, quando, a partir da chamada eugenia, se produziu um verdadeiro racismo científico que influenciou, inclusive, políticas de governo. A busca de um imaginário da ciência que não faça isto e, ao mesmo tempo, contemple questões como a de onde surgem para além dos métodos e das rotinas as ideias disruptivas, aquelas que mudam paradigmas ou pelo menos a direção da pesquisa, é um desafio. Parte da resposta não pode deixar de estar na capacidade de mobilizar eficazmente as paixões alegres (VELHO, 2019a; DELEUZE, 1981; 2015). Podemos até figurativamente celebrar imaginações alegres - que aumentem a potência de agir - em oposição às tristes, que despotencializam - e manipulam -, associáveis talvez, respectivamente, às pulsões freudianas de vida e de morte. Outra parte, consorciada à anterior, certamente estará em uma educação que não se prenda a um racionalismo estreito e que se negue a si mesma, mas saiba apelar para esse imaginário, ampliando e transformando o que hoje se denominam atividades extraclasses, de modo a transformar o próprio sentido da educação e estender o seu escopo para o conjunto da população, por exemplo, multiplicando autenticamente as perspectivas contempladas (VELHO, 2018b). Ainda poderemos procurar na imaginação dos artistas as 
metáforas que poderiam contribuir para entender o discurso da ciência - e não só o escrito -, aproximando, assim, razão e sensibilidade, o que de novo nos leva à questão da democracia.

Quanto ao mais, tratamos de, inspirados nesse e em outros exemplos, buscar reconhecer e conduzir o mais seguidamente possível o nosso próprio imaginário na direção da razão, a razão da ciência, mas também para além da ciência atual e com um vislumbre menos turvo do exterior da caverna. Para assim caminhar, no entanto, há de início que contarmos com uma reconciliação entre imaginação e razão.

\section{REFERÊNCIAS}

ATLAN, H.; BOUSQUET, C. Questões sobre a vida: entre o saber e a opinião. Lisboa: Instituto Piaget, 1996 [1994].

AURÉLIO, D. P. Imaginação e Poder: estudo sobre a filosofia política de Espinosa. Lisboa: Colibri, 2000.

DELEUZE, G. Spinoza: Philosophie Pratique. Paris: Les Éditions de Minuit, 1981.

En Medio de Spinoza. 2. ed. Buenos Aires: Cactus, 2015.

ESPINOSA, B. de. Tratado Teológico-Político. Tradução, introdução e notas de Diogo Pires Aurélio. Lisboa: Imprensa Nacional; Casa da Moeda, 1988 [1670].

Tratado Político. Tradução, introdução e notas de Diogo Pires Aurélio. Lisboa: Círculo de Leitores; Temas e Debates, 2011.

Ética. Tradução, introdução e notas de Diogo Pires Aurélio. Lisboa: Relógio D'Água Editores, 2020 [1677].

EVANS-PRITCHARD, E. E. Witchcraft, Oracles and Magic among the Azande. Oxford: Oxford University Press, 1937.

JAMES, S. Spinoza on Philosophy, Religion, and Politics: the Theological-Political Treatise. Oxford: Oxford Univesity Press, 2012.

MARX, K. H. Cuaderno Spinoza. Tradução, estudo preliminar e notas de Nicolás Gonzáles Varela. Barcelona: Montesinos, 2012.

NIETZSCHE, F. From On Truth and lie in an extra-moral sense. In: KAUfamanN, W. (org.). The Portable Nietzsche. Nova York: Vintage Books, 1980. p. $42-47$. 
SPINOZA, B. Obra Completa II: Correspondência Completa e Vida. São Paulo: Perspectiva, 2014.

VELHO, Otávio. O cativeiro da Besta-Fera. In: Mais Realista do que o Rei: ocidentalismo, religião e modernidades alternativas. Rio de Janeiro: Topbooks, 2007 [1995]. p. 103 - 133.

Reflexão etnográfica e experiência narrada sobre fronteiras de ciência(s). In: GEIGER, A. (org.). Antinomias do Real. Rio de Janeiro: Editora UFRJ, 2018a. p. 383 - 394.

Ciência, modernidade, identidade: diálogo entre saberes. In: GEIGER, A. (org.). Antinomias do Real. Rio de Janeiro: Editora UFRJ, 2018b. p. $115-125$.

Passos na constituição de um paradigma ecológico: de Bateson a Ingold. In: GEIGER, A. (org.). Antinomias do Real. Rio de Janeiro: Editora UFRJ, 2018c. p. 129 - 135.

Religião, Política e Paixões: a contemporaneidade de Espinosa. Síntese: revista de filosofia. Belo Horizonte, v. 46, n. 145, p. $241-253$, 2019a.

Roteiro de Busca: sobre a contemporaneidade de Karl Mannheim. Tensões Mundiais, Fortaleza, v. 15, n. 29, p. 17 -44, 2019b.

O social e o além do social: alguns fios de uma questão ontológica e ética. Debates do NER, Porto Alegre, v. 1, n. 37, p. 112 - 124, 2020. 